ISSN 1561-8358 (Print)

ISSN 2524-244X (Online)

UDC 620.179 .15

Received 19.08.2021

https://doi.org/10.29235/1561-8358-2021-66-4-505-512

Поступила в редакцию 19.08.2021

\author{
Sergei A. Zolotarev ${ }^{1}$, Valery L. Vengrinovich ${ }^{1}$, Sergei I. Smagin ${ }^{2}$ \\ ${ }^{1}$ Institute of Applied Physics of the National Academy of Science of Belarus, Minsk, Republic of Belarus \\ ${ }^{2}$ Computing Center of the Far Eastern Branch of the Russian Academy of Sciences, Khabarovsk, Russian \\ Federation
}

\title{
ITERATIVE TOMOGRAPHY OF PIPES DURING OPERATION
}

\begin{abstract}
The pipe wall thickness was estimated based on three-dimensional images of the pipe recovered from several X-ray projections, which were made in a limited angle of view. Since the effects of scattered radiation and beam hardening are up to $50 \%$ of the main radiation, ignoring them leads to blur of the image and inaccuracy in determining dimensions. To restore pipe images from projections, a volume and/or shell representation of the pipe is used, as well as iterative Bayesian methods. Using these methods, the error in estimating the pipe wall thickness from the projection data can be equal to or less than $300 \mu \mathrm{m}$. It has been shown that standard X-ray projections on the film or imaging plates used to obtain data can be used to restore pipe wall thickness profiles in factory conditions.

Keywords: iterative methods, image reconstruction, tomography, image processing, image enhancement, Bayesian method

For citation: Zolotarev S. A., Vengrinovich V.L., Smagin S.I. Iterative tomography of pipes during operation. Vestsi Natsyyanal'nai akademii navuk Belarusi. Seryya fizika-technichnych navuk = Proceedings of the National Academy of Sciences of Belarus. Physical-technical series, 2021, vol. 66, no. 4, pp. 505-512. https://doi.org/10.29235/1561-8358-2021-66-4-505-512

\author{
С. А. Золотарев ${ }^{1}$, В.Л. Венгринович ${ }^{1}$, С.И. Смагин ${ }^{2}$ \\ ${ }^{1}$ Институт прикладной физики Национальной академии наук Беларуси Республики Беларусь, Минск, \\ Республика Беларусь \\ ${ }^{2}$ Вычислительный иентр Дальневосточного отделения Российской академии наук, Хабаровск, Российская Федерация
}

\section{ИТЕРАЦИОННАЯ ТОМОГРАФИЯ ТРУБ В ПРОЦЕССЕ ЭКСПЛУАТАЦИИ}

Аннотация. Проведена оценка толщины стенки трубы, исходя из трехмерных изображений трубы, восстановленных из нескольких рентгеновских проекций, которые были выполнены в ограниченном угле обзора. Поскольку эффекты рассеянного излучения и ужесточения лучей составляют до 50 \% от основного излучения, их игнорирование приводит к размытию изображения и неточности при определении размеров. Для восстановления изображений труб из проекций применяются объемное и/или оболочечное представление трубы, а также итеративные байесовские методы. При использовании этих методов ошибка оценки толщины стенки трубы из проекционных данных может быть равной или меньше 300 мкм. Показано, что полученные рентгеновским излучением стандартные проекции на пленке или визуализирующих пластинах, применяемых для получения данных, могут использоваться для восстановления профилей толщин стенок труб в заводских условиях.

Ключевые слова: итерационные методы, реконструкция изображений, томография, обработка изображения, улучшение изображения, байесовский метод

Для цитирования: Золотарев, С. А. Итерационная томография труб в процессе эксплуатации / С. А. Золотарев, В.Л. Венгринович, С.И. Смагин // Вес. Нац. акад. навук Беларусі. Сер. фіз.-тэхн. навук. - 2021. - Т. 66, №4. C. 505-512. https://doi.org/10.29235/1561-8358-2021-66-4-505-512

Introduction. There are a number of industrial areas, such as chemical and petrochemical, energy, pipeline transport, where accurate estimates of the thickness of the walls of transporting pipes as well as the detection of defects in the solidity of pipes is a problem of the viability of the design and its safety. Often these assessments require a combination of several non-destructive control techniques, such as vortex, ultrasound and X-ray. Note that the object of the type "pipe" belongs to the class of bite-homogeneous objects of control.

All the methods considered, except those based on X-rays, can be used only with sensors that are either directly inserted into the controlled tube or there is a possibility of direct contact with the outer surface of the pipe.

(С) Золотарев С.А., Венгринович В. Л., Смагин С.И., 2021 
X-ray radiography allows contactless examination of the outer and inner surface of the pipe, but accurate estimates of corrosive and other damage to the pipe are not possible according to the radiograms used by X-ray methods give only a flat image of the 3D pattern and therefore the estimates made with their help are very approximate. On the X-ray, the shadows of the internal structures are superimposed on each other and mask important fragments of the pipe, much less minor defects. In the tomographic image, the internal structure of the pipe is reproduced without overlays, materials of different density and composition clearly differ. The dimensions of any inaccessible cavity and walls can be measured with high accuracy. That is, the problem could be solved by obtaining and analyzing three-dimensional tomographic images of pipes, but classical computed tomography is not applicable with limited access to the tube - a case that actually exists in practice.

The greatest application in the task - total thicknessometry - has ultrasound, but the laboriousness of the method when working with large surfaces of the pipe and the need for good contact of the sensor with the surface limit the scope of its application. Film and digital X-rays are also possible, but due to these limitations and the need to use a powerful source - radiation, $\gamma$ for example, Ir-192 with a short half-life, have not yet found widespread use. These restrictions apply entirely to the defectoscopy of ring welded tubes.

Iterative image reconstruction. Let us consider the problem of reconstructing a two-dimensional tomographic image as an ill-posed inverse problem aimed at solving the following operator equation:

$$
p=Q \mu+\eta
$$

where $p=p(y)$ is the measured data in the time or space domain; $Q$ is an operator that translates input data into output, or one of the types of hardware functions; $\mu=\mu(x)$ is the vector of the desired distribution of unknown values and $\eta(y)$ is the random noise superimposed on the input data. In the linear finite-dimensional case considered below, the operator $Q$ is defined using an order matrix with real elements $Q_{i j}=Q\left(y_{i}, x_{j}\right)$ and acts from the Euclidean space $R^{n}$ into the space $R^{m}, \mu=\left(\mu_{1}, \mu_{2}, \ldots \mu_{n}\right), p=\left(p_{1}\right.$, $\left.p_{2}, \ldots p_{m}\right)$. There are many different situations in which the operator equation (1) has no solution in the classical sense. In such cases, although the classical solution to Eq. (1) does not exist, one can seek its generalized solution, or the so-called pseudo solution, which can be obtained by solving the optimization problem, which, in the simplest case, leads to the minimization of the quadratic functional. Let us define a pseudo solution of problem (1) from the condition:

$$
J(\tilde{\mu})=\inf \left\{J(\mu): \mu \in R^{n}\right\}, J(\mu)=\|Q \mu-p\|_{R^{m}}^{2},
$$

where $Q \mu$ are the model data obtained based on the solution of the direct problem. The pseudo-solution $\tilde{\mu}$ may not be unique, however, among the solutions with the minimum norm (2), it is the only one.

For an approximate search for a pseudo-solution, the idea of optimizing the data processing by minimizing some a priori functional weighted using the regularization parameter $\alpha>0$ turned out to be useful:

$$
R_{\alpha}(\mu)=J(\mu)+\alpha B(\mu)
$$

The functional $B(\mu)$ imposes quality constraints on the solution. They are specified either as the sum of squares of adjacent elements of the reconstructed object $\sum \mu_{j}^{2}$ or as a sum (maximum entropy method) $\sum \mu_{j} \log \mu_{j}$, which is the entropy of discretely distributed elements that have values. Entropy is used as a priori knowledge, providing a way for the most unbiased assignment of an a priori functional. By minimizing the functional, a stable approximate pseudo-solution $\tilde{\mu}_{\alpha}$ can be obtained:

$$
R_{\alpha}\left(\tilde{\mu}_{\alpha}\right)=\inf \left\{R_{\alpha}(\mu): \mu \in R^{n}\right\},
$$

where $\tilde{\mu}_{\alpha} \rightarrow \tilde{\mu}$ at $\alpha \rightarrow 0$. The inclusion of the a priori expected probability distribution in the calculations makes it possible to reduce the effect of uncertainty in the experimental data. The probabilistic rule for probabilistic information processing is based on the Bayesian theorem for calculating the conditional probability, which is written as:

$$
P(\mu \mid p)=\frac{P(p \mid \mu) P(\mu)}{P(p)},
$$

where $P(\mu \mid p)$ is the posterior probability distribution, $P(p \mid \mu)$ is the probability function, which formally describes the response of the measuring system, taking into account noise; $P(p)$ is the unconditional 
probability of the experimental data. Here it is considered as a global normalization constant given by a rule $P(p)=\Sigma P(p \mid \mu) P(\mu)$, and $P(\mu)$ is an a priori probability distribution. Thus, in order to calculate the most probable unknown solution, it is necessary to maximize the expression $P(\mu \mid p)$. In the probabilistic approach, image reconstruction begins with maximizing the Bayesian conditional probability according to expression (5). This maximization operation is equivalent to minimizing the following functional:

$$
\min :-\log P(\mu \mid p)=-\log P(p \mid \mu)-\alpha \log P(\mu),
$$

where the Gaussian noise can be estimated as follows:

$$
\inf \left\{-\log P(p \mid \mu): \mu \in R^{n}\right\}=J(\tilde{\mu}) .
$$

The expression on the right can be interpreted as the root mean square variance of the entire image. The $-\log P(\mu)$ term is the informational negative entropy. This qualitative characteristic can include: homogeneity, the presence of a limited number of dissimilar phase inclusions, the property of positivity of the numerical values of the linear attenuation coefficients in voxels, etc. The quality of the input information can be estimated using the unconditional probability of the input data $P(p)$. The relatively small value of $P(p)$ is, as a rule, the result of poor compatibility of a priori information, which does not cover all input data. However, an extremely large value of $P(p)$ greatly expands the configuration space and, thus, leads to difficulties associated with poor convergence of the iterative procedure and, accordingly, too high computational costs.

Good results are obtained by using iterative tomographic algorithms using total variation (TV) as a regularizing functional [5]. The total variation method has provided new opportunities for iterative tomography, which makes it possible to successfully reconstruct images by minimizing the TV seminorm even with a limited number of noisy projections. The use of minimizing the total variation of the reconstructed image makes it possible to eliminate artifacts caused by noise in X-ray projections arising from the low current of the X-ray tube. In addition, the use of total variation provides almost complete elimination of bandpass artifacts caused by a decrease in the number of projections.

Tomography of limited number of projections at incomplete angle of view. During the tomographic reconstruction, a set of X-ray projection images is transformed into many flat sections of the three-dimensional tomographic image, which is a laborious computational procedure. The Institute of Applied Physics of the National Academy of Science of Belarus has developed software that allows parallel reconstruction for spiraling, fan and conical geometry of shooting. The software is designed for Windows XP, 64 bit, Windows 7, 64 bit and Windows 8, 64 bit.

Internal defects such as cracks, voids and foreign inclusions can have a significant impact on the reliability and quality of industrial products. With our state-of-the-art tomographic software, we can give you a look inside your product and show you in three-dimensional form why they don't meet the requirements.

Our experience allows us to correctly assess complex 3D digital images and correctly diagnose the problem by identifying defects up to the micron level. Usually, the study of the internal structure of the object cannot be achieved without the destruction of the object itself. This study is crucial for identifying defects in substandard products, such as identifying voids and cracks. When the sample is cut into several parts in order to find these defects. New defects can be introduced, the original sample is destroyed, and therefore there is a risk that the defect will not be detected due to the fact that the cutting of part of the sample was done in the wrong place.

3D imaging, applied simultaneously with the software for tomographic reconstruction, is an alternative to destructive control methods, as the controlled object can be investigated in its entirety, and the result of tomographic reconstruction provides a full three-dimensional representation of the necessary spatial area, both inside and outside the object. The software is designed to collect input projection data at different positions of the radiation source and different scanning geometries.

Two-dimensional wrapping tomography of the longitudinal profile of the pipe.

Purpose: Reconstruct the longitudinal image of the pipe and measure the thickness of the walls with an accuracy of $0.5 \mathrm{~mm}$.

The wording of the problem: Overcoming mathematical degeneration: The prospective viewing angle of the object is too small to accurately recover the image of the four surface pipes (Figure 1). 


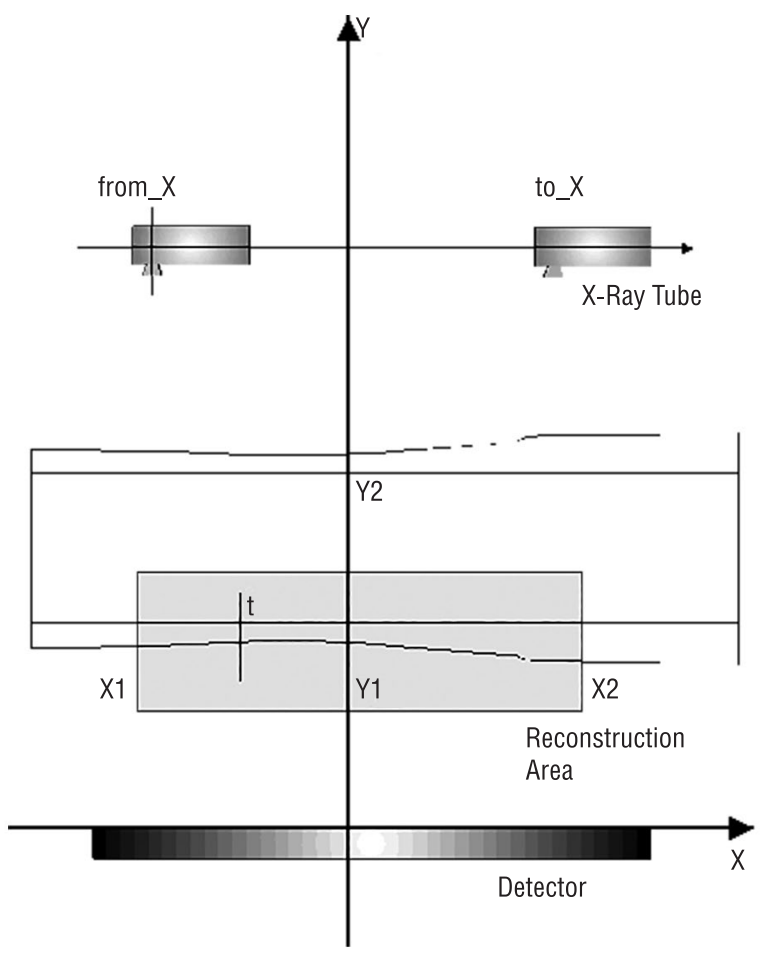

Figure 1. Scan geometry for reconstruction longitudinal profile pipes

The Federal Institute of Materials Science and Diagnostics (Germany, Berlin) has developed a tomographic radiometry system TomoCAR, adapted to a wide range of pipe diameters and allows automatic obtaining a set of flat X-ray images of longitudinal section of the pipe in the corner of the view, limited to $40-45^{\circ}$. The pixel is 83 microns, with a total length of 1,856 pixels $(0.4 \mathrm{~mm} \times 1.5 \mathrm{~mm})$. The mechanized radiometric system was created to inspect the ring seams. Its main task is to detect and assess the size of $176 \mathrm{~mm} 500 \mathrm{~mm}$ the cracks. The X-ray source moves along the longitudinal axis of the pipe. At the same time, in one pass it produces up to 1200 pulses of radiation recorded by the linear matrix of detectors.

The main problem is that in the planning tomography due to the acute lack of data due to the small angle of view (only $35-45^{\circ}$ instead of the required $180^{\circ}$ ) reconstruction by filtered reverse projections (FBP) allows only a greased image of a pipe with a large number of artifacts.

In the Computational Diagnostics Laboratory of the Institute of Applied Physics of the National Academy of Science of Belarus, in cooperation with the Federal German Institute of Materials Science and Diagnostics, an application software package was developed, providing reconstruction of the profile of the inner and outer surfaces of the pipes with the help of the system of mechanized radiometry TomoCAR. The software interface provides input of the raw data and the task of parameters of preprocessing and reconstruction, both for scanning along the pipe axis, and for the sequential removal of a set of such scanned data while rotating the scanner around the axis of the pipe with a given angular step, which provides reconstruction of the internal and outer surfaces of the pipe.

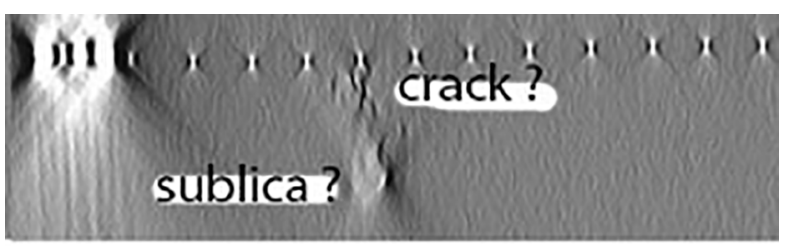

Computational resources were allocated by the Russian side [6].

Examples of pipe profile reconstruction. The reconstruction technology for tomoCAR's mechanized X-ray projection system was designed by Institute of Applied Physics. However, due to the use of smoothing prior information, the resolution

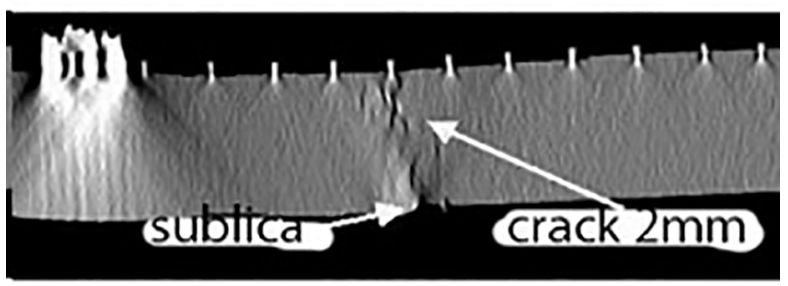
may not be sufficient $0.5 \mathrm{~mm}$ to detect particularly minor defects. In the upper zone of the picture, the result of the reconstruction of the pipe by the FOP method is shown, on the lower zone - the result of the reconstruction of the same section of the pipe by the method of wrapping reconstruction, and in the middle - the image obtained by merging the two previous images (Figure 2).

An important addition to the previously described tomographic methods of reconstruction based on limited data is the method of three-dimensional wrapping reconstruction, which allows reconstruction of the inner and outer surface of the pipe, which is in operation even with unilateral access to it. 
Reconstruction of the inner surface of the pipe by five projections. The proposed technique was tested on a sample from the German Institute of Materials Science and Diagnostics, which was a steel

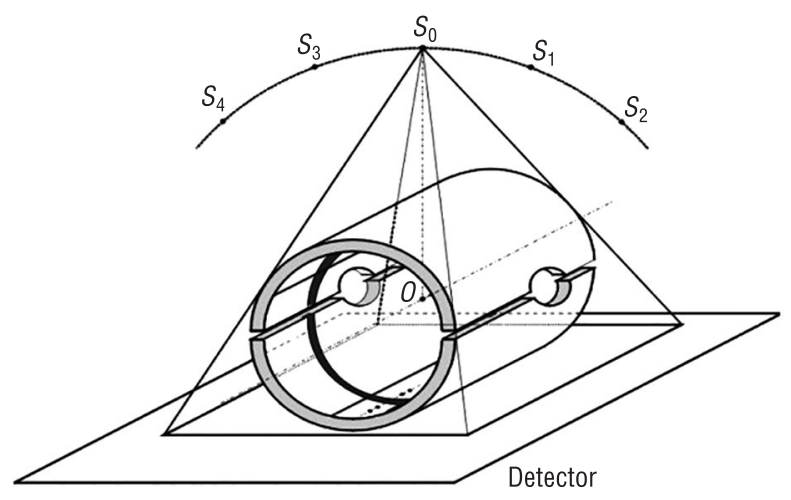

Figure 3. X-ray data collection scheme. Spatial positions of the radiation source are depicted in the arc segment. Under them a test tube is shown underlying the X-ray film pipe. To test the resolution of the algorithm, four delays were attached to the inner surface of the pipe $3.6 \mathrm{~mm}, 1.8,1.4,1.25,0.8 \mathrm{~mm}$.

For this geometry, the source of radiation can be considered a point, i.e. the X-ray was carried out by a conical beam. The linear weakening of the pipe material was transferred to a larger grid for reconstruction. The image size was $593 \times 299$ pixels. Discretization of the inner surface $\mu^{-1}$ is $0.2 \mathrm{~mm}$, on the corner -1200 points, and on the axis residents 213 points $(0.3$ degrees and $0.3 \mathrm{~mm}$ and $0.1 \mathrm{~mm}$ - the size of intervals on the corner and coordinate) (Figures 3,4). The computation time on modern computers is about 10 to 15 minutes.
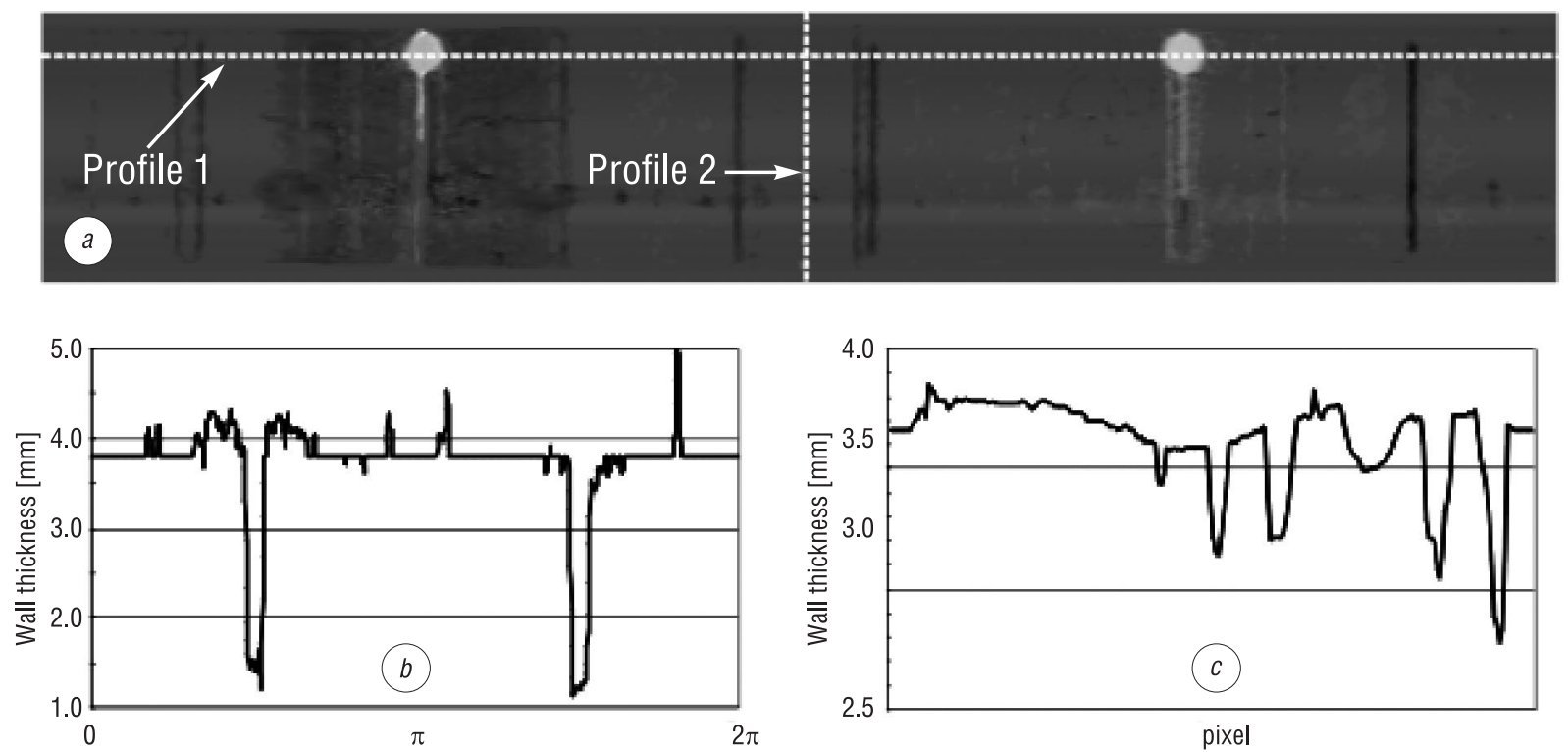

Figure 4. Reconstruction results: gray value representation of inner pipe surface together with pipe profile along the circle (a), thickness profile $1(b)$ and profile $2(c)$ along pipe axis

Three-dimensional tomography taking into account a priori information. In industrial X-ray imaging, the input of the data and the limited range of the views require optimal accounting of all available a priori information. It is known that the main problems of industrial tomography are:

1) limited viewing angle,

2) low number of projections

3) translucence by a diverging conical beam.

The challenge is to use the maximum pre-found prior information about the solution you're in. In the process of image reconstruction, the information is numerically transformed, which involves its distortion, as it involves discreteization. When a mathematical model is replaced with a discrete model, the original information is distorted. Iterative account and rounding errors distort the information as it is numerically converted. The more complex the task, the more distortions of information in its numerical solution is, the less reliable is the result of the decision. Attempts to achieve the desired accuracy by reducing the step of the grid lead to an increase in the number of unknowns. At the same time, the amount of calculations increases dramatically, and, consequently, the accumulation of errors appears. 

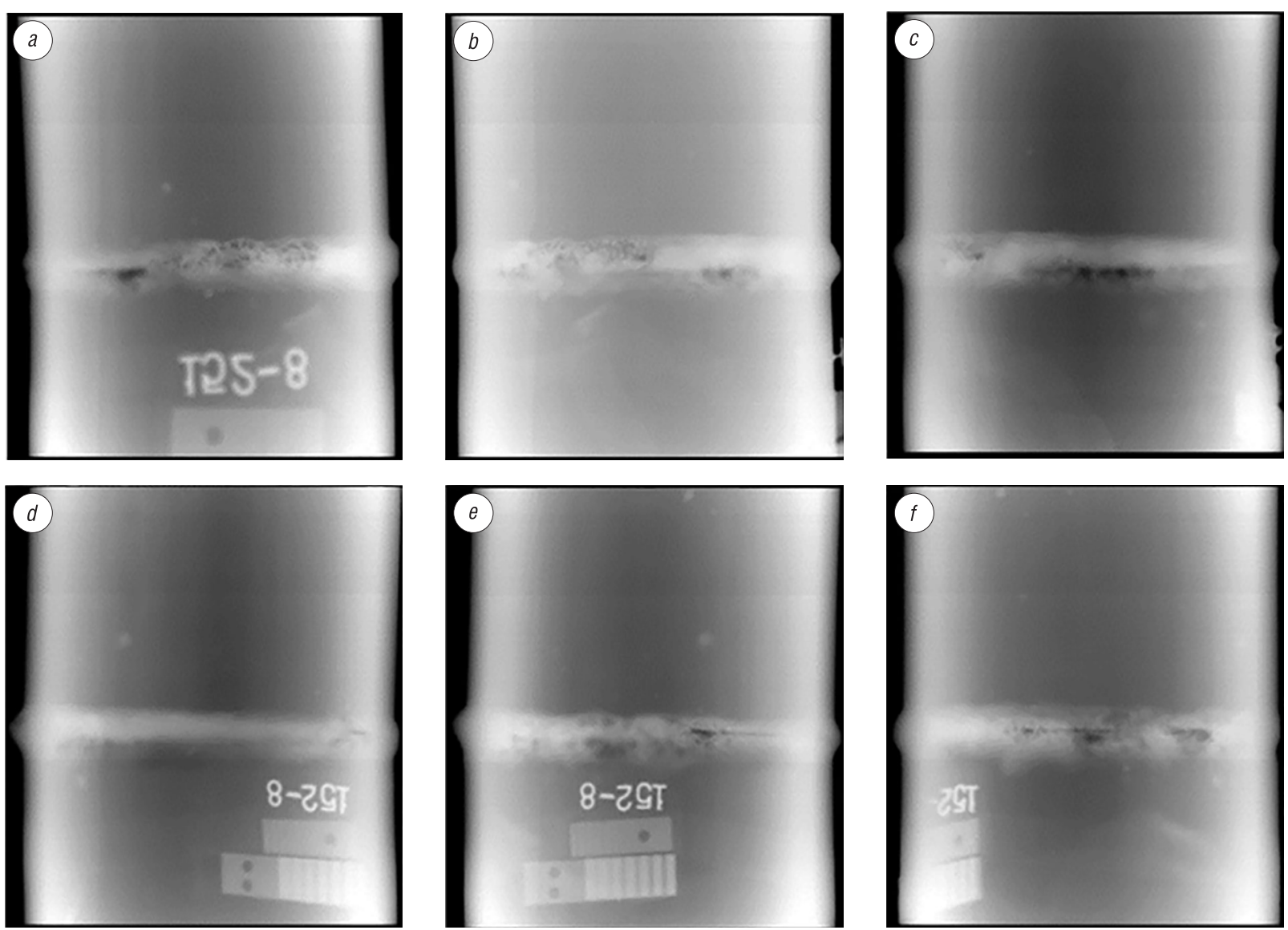

Figure 5. X-ray projections of the test tube: $a$-projection for $0^{\circ}, b$ - projection for $45^{\circ}, c$ - projection for $90^{\circ}, d$-projection for $135^{\circ}, e$ - projection for $180^{\circ}, f$ - projection for $225^{\circ}$
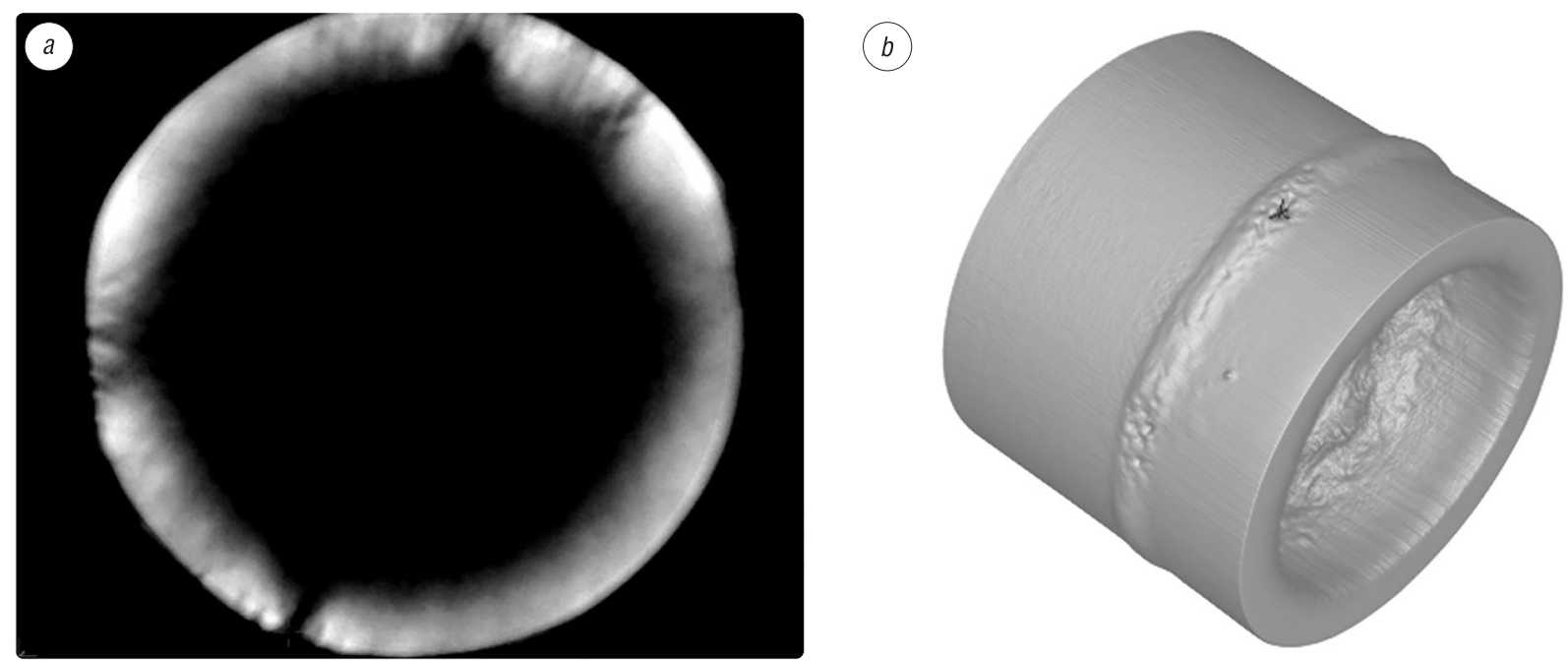

Figure 6. Cross section $(a)$ and a promising view $(b)$ of the reconstructed pipe image

However, additional prior information about the integral properties of the object under study can be added to the theoretical model. The introduction of a priori information narrows the function class in which a solution is sought, reduces computation, and creates restrictions on random misrepresentation of information when you score. As a rule, industrial objects are bit-and-homogeneous objects consisting of the final number of different materials. For example, industrial pipelines can be considered as three-phase objects consisting of steel or cast iron, insulation and leaking liquid, or some gaseous phase (steam or gas). 

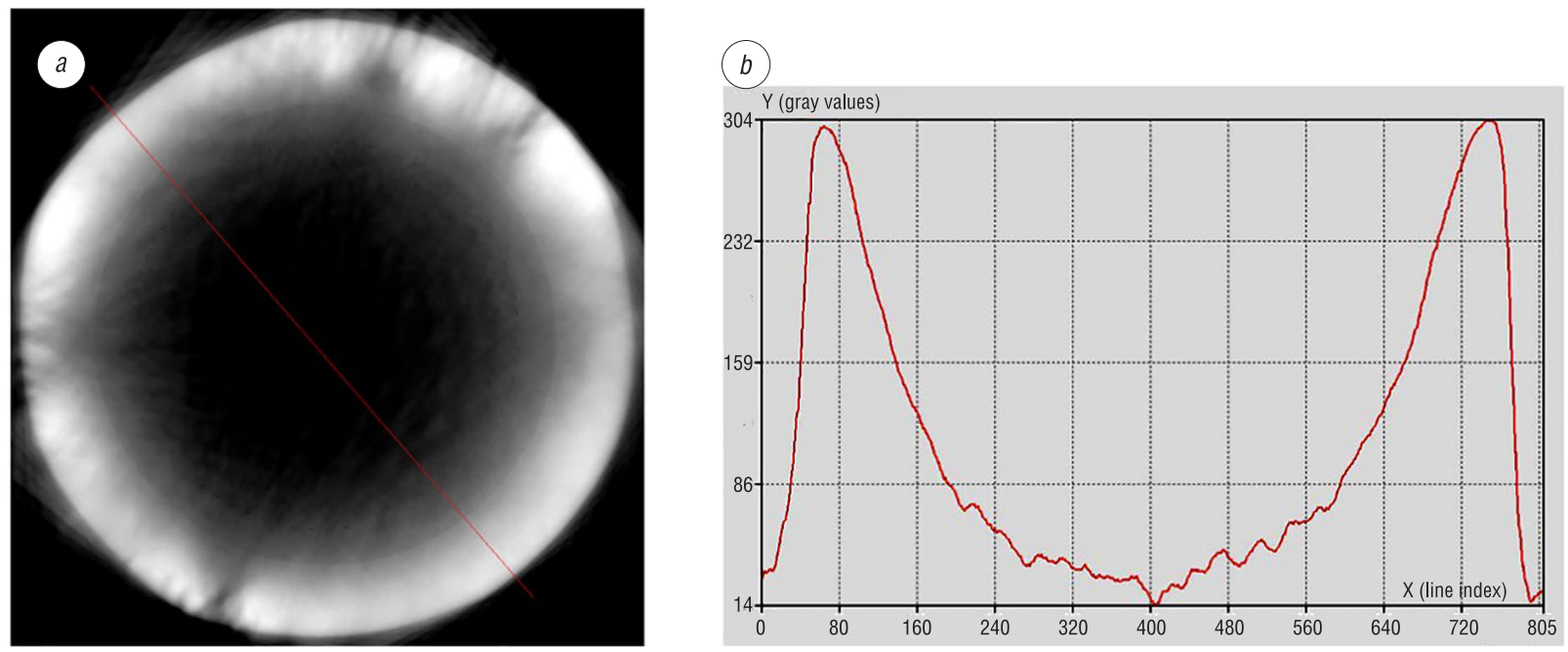

Figure 7. Cross section of the pipe (a) and its profile along the line (b) running through its center
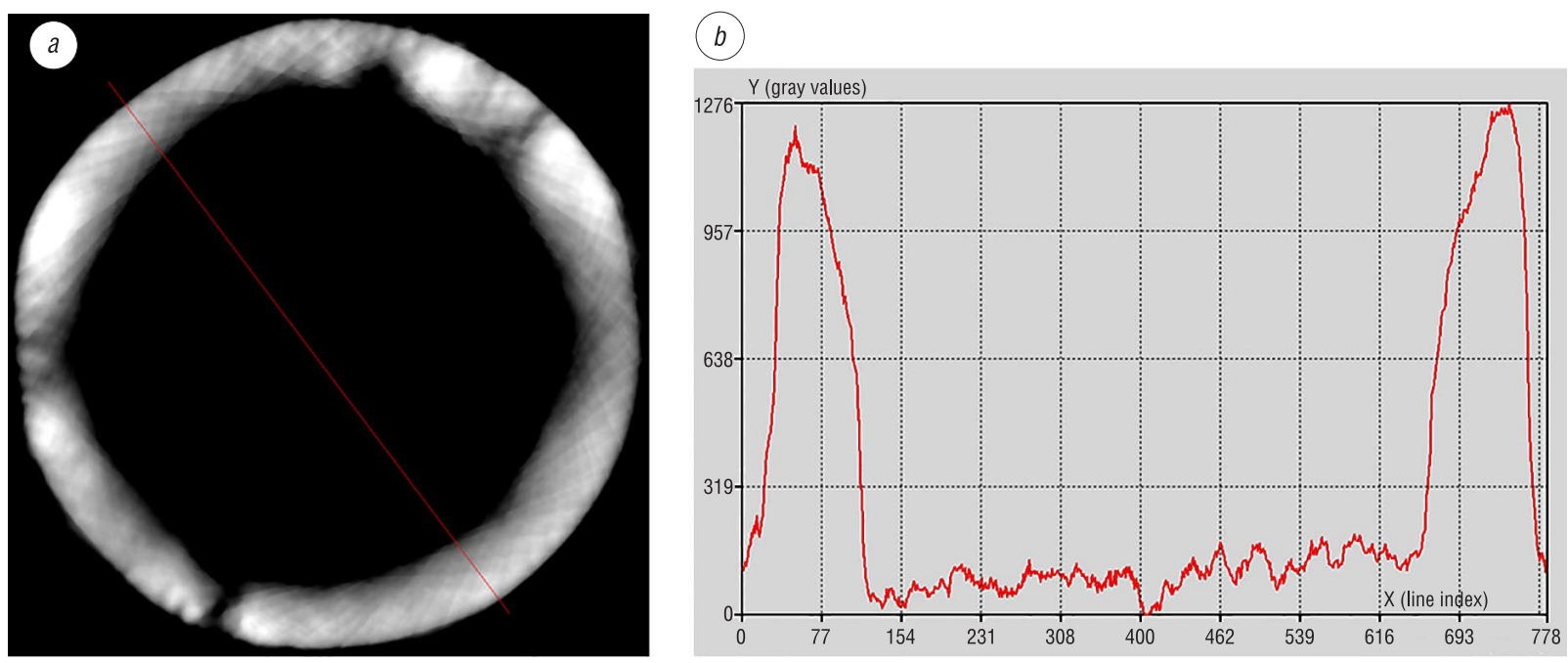

Figure 8. Cross-section of the pipe (a) and its profile along the line $(b)$ running through the center of the pipe

For such objects, the quality of tomographic reconstruction can be significantly improved by using iterative algorithms using total variation as a regulatory function. The total variation method has provided new possibilities of iterative tomography, allowing successfull reconstruction of images by minimizing TV even with a limited number of noisy projections.

Below, Figure 5 shows five X-ray projections of a pipe with a diameter $89 \mathrm{~mm}$ and a wall with thickness of $10 \mathrm{~mm}$, obtained at the Mozyr Oil Refinery. The lack of energy of the X-ray source caused a strong blur on the X-ray projections due to the effects of scattering and the tightening of X-rays.

Figure 6 shows a cross section of the pipe in the weld area and a promising image of the pipe. Note that this image is unsuitable for virtual measurements (Figure 7). The application of the method of a total variation of the [5] has provided the necessary reconstruction (Figure 8).

Conclusions. The proposed tomographic reconstruction technique can be applied to the wall thickness determination for corroded pipes. For this purpose only a couple of projections within limited observation angle are sufficient to get accurate measures. The measurement error of less than $0.3 \mathrm{~mm}$ can be reached. The accuracy of the technique can be improved by extracting the contribution of concomitant effects like scattering and background radiation from the exposed image.

Finally, the conclusion can be drawn that standard projection techniques using X- or $\gamma$-rays in combination with X-ray film or imaging plates can be applied for the data acquisition to reconstruct wall thickness profiles in an in-field environment. 


\section{Acknowledgments}

This work was funded by the Federal Ministry for Economic Affairs and Energy (Federal Republic of Germany) and the National Academy of Sciences of Belarus.

This work was funded by the Federal Ministry of Economics of Germany and the National Academy of Sciences of Belarus. The studies were carried out using the resources of the Center for Shared Use of Scientific Equipment "Center for Processing and Storage of Scientific Data of the Far Eastern Branch of the Russian Academy of Sciences", funded by the Ministry of Science and Higher Education of the Russian Federation (project No. 075-15-2021-663).

\section{Благодарности}

Работа выполнена при финансовой поддержке Федерального министерства экономики и энергетики Германии и Национальной академии наук Беларуси.

Исследования проводились с использованием ресурсов Центра коллективного пользования научным оборудованием «Центр обработки и хранения научных данных Дальневосточного отделения Российской академии наук», финансируемого Министерством науки и высшего образования Российской Федерации (проект № 075-15-2021-663).

\section{References}

1. Vengrinovich V.L., Zolotarev S. A. Iterative Methods in Tomography. Minsk, Belaruskaya navuka Publ., 2009. 227 p. (in Russian).

2. Vengrinovich V.L., Denkevich J.B., Tillack G.-R., Nockeman C. Multistep 3D X-ray Tomography from a Limited Number of Projections and Views. Tompsonand D. O., Chimenti D. E., eds. Review of Progress in Quantitative Nondestructive Evaluation. New York, Plenum Press, 1997. Vol. 16, pp. 317-323. https://doi.org/10.1007/978-1-4615-5947-4_41

3. Vengrinovich V.L., Denkevich J. B., Tillack G.-R. Limited Projections and Views Bayesian 3D Reconstruction Using Gibbs Priors. Proceedings $7^{\text {th }}$ European Conference on Non-destructive Testing (ECNDT'98), Copenhagen, 26-29 May 1998. Copenhagen, 1998, pp. 2371-2378.

4. Linden W. von der. Maximum-entropy data analysis. Applied Physics A, 1995, vol. 60, no. 2, pp. 155-165. http://dx. doi.org/10.1007/BF01538241

5. Jia R. Q., Zhao H. Q. A Fast Algorithm for the Total Variation Model of Image Denoising. Advances in Computational Mathematics, 2010, vol. 33, no. 2, pp. 231-241. https://doi.org/10.1007/s10444-009-9128-5

6. Sorokin A. A., Makogonov S. V., Korolev S.P. Information Infrastructure for Collective Scientific Work in the Far East of Russia. Scientific and Technical Information Processing, 2017, vol. 44, no. 4, pp. 302-304. https://doi.org/10.3103/ s0147688217040153

\section{Information about the authors}

Sergei A. Zolotarev - D. Sc. (Engineering), Chief Researcher, Institute of Applied Physics of the National Academy of Sciences of Belarus (16, Akademicheskaya Str., 220072, Minsk, Republic of Belarus). https://orcid.org/00000002-1498-0658. E-mail: sergei.zolotarev@gmail.com

Valery L. Vengrinovich - D. Sc. (Engineering), Professor, Head of the Laboratory of Computing Diagnostics, Institute of Applied Physics of the National Academy of Sciences of Belarus (16, Akademicheskaya Str., 220072, Minsk, Republic of Belarus). https://orcid.org/0000-00015413-802X. E-mail: veng@iaph.bas-net.by

Sergei I. Smagin - Corresponding Member of the Russian Academy of Sciences, D. Sc. (Physics and Mathematics), Professor, Director of Computing Center of the Far Eastern Branch of the Russian Academy of Sciences (65, Kim Yu Chen Str., 680000, Khabarovsk, Russian Federation). https://orcid.org/0000-0002-1879-8829. E-mail: smagin@ccfebras.ru

\section{Информация об авторах}

Золотарев Сергей Алексеевич - доктор технических наук, главный научный сотрудник, Институт прикладной физики Национальной академии наук Беларуси (ул. Академическая, 16, 220072, Минск, Республика Беларусь). https://orcid.org/0000-0002-1498-0658. E-mail: sergei.zolotarev@gmail.com

Венгринович Валерий Львович - доктор технических наук, профессор заведующий лабораторией вычислительной диагностики, Институт прикладной физики Национальной академии наук Беларуси (ул. Академическая, 16, 220072, Минск, Республика Беларусь). https://orcid. org/0000-0001-5413-802X. E-mail: veng@iaph.bas-net.by

Смагин Сергей Иванович - член-корреспондент Российской академии наук, доктор физико-математических наук, профессор, директор вычислительного центра Дальневосточного отделения Российской академии наук (ул. Ким Ю Чена, 65, 680000, Хабаровск, Российская Федерация). https://orcid.org/0000-0002-1879-8829. E-mail: smagin@ccfebras.ru 